\title{
Editorial: Flexibility in the Migration Strategies of Animals
}

\author{
Nathan R. Senner ${ }^{1 *}$, Yolanda E. Morbey ${ }^{2}$ and Brett K. Sandercock ${ }^{3}$ \\ ${ }^{1}$ Department of Biological Sciences, University of South Carolina, Columbia, SC, United States, ${ }^{2}$ Department of Biology, \\ Western University, London, ON, Canada, ${ }^{3}$ Department of Terrestrial Ecology, Norwegian Institute for Nature Research, \\ Trondheim, Norway
}

Keywords: conservation, developmental plasticity, environmental change, phenotypic flexibility, phenotypic plasticity

\section{Editorial on the Research Topic}

Flexibility in the Migration Strategies of Animals

\section{INTRODUCTION}

Climatic and environmental changes are global phenomena, altering every biome, and affecting nearly every species. At a population level, significant effort has been devoted to identifying demographic "winners" and "losers" in the face of rapid environmental change (Wiens, 2016). Armed with information on population status, a major focus in evolutionary ecology has been to attribute organismal responses to behavioral or physiological processes (i.e., phenotypic plasticity and flexibility), genotypic change, or some combination thereof (Gienapp et al., 2008). Migratory species may be especially vulnerable to environmental change because they often have life-history strategies characterized by low fecundity and high survival, because long distance movement exposes them to many different types of risk, and because they require patches of habitat separated by vast distances (Wilcove and Wikelski, 2008). Accordingly, the dramatic environmental changes that have occurred during the Anthropocene have led to rapid population declines for many migrants (Lascelles et al., 2014; Pearce-Higgins et al., 2017; Tucker et al., 2018). Nevertheless, some migratory species have maintained stable population sizes and displayed surprising levels of phenotypic flexibility (Pedler et al., 2018), phenotypic plasticity (Eichhorn et al., 2009; Verhoeven et al., 2018), and even evolutionary adaptability (Kovach et al., 2012; Helm et al., 2019). In light of these organismal responses, significant questions remain about the degree to which migratory species can adapt to change, both in the short term and across generations (Hebblewhite and Haydon, 2010; Piersma, 2011).

For our Research Topic on Flexibility in the Migration Strategies of Animals, we invited a wide array of conceptual, theoretical, and empirical papers. Our intention was to develop a more complete understanding of the degree of variation in migratory behaviors exhibited by individuals and populations, so that we could further our ability to project how future environmental change might affect the population dynamics of migratory species. To conceptually organize our topic and evaluate the timescales over which individuals and populations can respond to environmental change, we adopted an ontogenetic approach to the study of migration. An ontogenetic approach recognizes that traits can have a genetic basis, but argues that different phenotypic traits can have varying degrees of lability over the course of an individual's lifespan. For instance, traits can fall anywhere along a continuum of lability, from traits that are canalized and immutable, to traits that are plastic but become fixed during specific windows of development (e.g., developmental plasticity), and those that remain flexible and can be reversibly changed at any life stage (e.g., phenotypic flexibility; Piersma and Drent, 2003). As a result, environmental change that 
is encountered at different points during an individual's life and affecting different traits will potentially have different consequences for individuals and populations (Senner et al., 2015). Such an ontogenetic approach is particularly important when considering migratory species with annual movements that traverse entire hemispheres and make it difficult to determine where and when environmental change is having the most dramatic effect on a population (Norris and Taylor, 2006).

Our Research Topic resulted in a collection of 30 peerreviewed articles that consider a broad range of taxa and a variety of migratory behaviors, from partial and differential migration to some of the champions of extreme long-distance migration. The articles also span a range of topics, from the development of new theory to the documentation of intra- and interspecific differences in migratory behaviors; the physiological, ecological, and evolutionary drivers of those patterns; and the implications of flexible migration for the development of improved management and conservation actions. Here, we review the contributions of the articles to four major topics in migration ecology: Theory, Pattern, Process, and Synthesis and Applications. By organizing the articles into these four categories, we highlight how the collection provides an important framework for the study of animal migration and furthers our understanding of the potential responses of migratory species to a changing world.

\section{THEORY}

The study of animal migration has a long history in the theoretical literature of ecology and evolutionary biology, dating back to early attempts to identify the important physical and environmental factors that affect the migratory behavior of birds (Alerstam, 1979). Theoretical investigations remain an active field and have been used to refine hypotheses about observed patterns, as well as drive new empirical work. For example, population dynamic models have been useful for understanding the cues used by individuals to make their migratory decisions (Budaev et al., 2019), the degree to which events occurring during one part of the year may have ramifications for events occurring in entirely different locations and at different times of the year (Taylor and Stutchbury, 2016; Taylor, 2017), and the configuration of events that leads to an optimal organization of the migratory annual cycle (Schmaljohann and Both, 2017; Lindström et al., 2019; Pirotta et al., 2019).

New theoretical papers in our Research Topic build upon these themes and make important contributions to our understanding of migratory strategies in seasonal environments. Morbey and Hedenström, for instance, constructed an optimization model to investigate whether migratory species should alter their departure timing from non-breeding sites or the speed of their migration as a means to optimize their arrival timing at their breeding areas. In general, they found that earlier departure should be the primary mechanism underlying earlier arrival timing (e.g., in males vs. females), although as migration distances become longer, both an earlier departure and faster migration should be beneficial.
Whereas the models in Morbey and Hedenström treated migration-related traits as locally adapted features of a migratory system, Oudman et al. explored finer scale aspects of migratory decision making. To do so, they used individual-based simulation models to explore the decision rules that account for Barnacle Geese (Branta leucopsis) switching among stopover sites in consecutive years while migrating from non-breeding sites in continental Europe to arctic breeding sites at Svalbard. They found that social interactions, combined with flexible responses to the densities of other geese encountered at stopover sites, determined an individual's decision-making process, thus enabling birds to maximize their fueling rates and expedite their northward migrations (Tombre et al., 2019).

The density-dependent responses of Barnacle Geese during migration suggest intriguing flexibility in stopover site use and indicate that even a population's migratory route itself may frequently be in flux. Links between competition and patterns of migration were also supported by an innovative network population model developed by Taylor, which showed that the strength of density-dependent population regulation during the breeding and non-breeding seasons, along with natal dispersal, can drive variation in patterns of migratory connectivity across populations.

This suite of theoretical studies suggests that a population's current migratory patterns are a product of a complex array of factors, and that as ecological drivers of migration undergo change, so too will the patterns of animal migration. Identifying such processes in action, though, requires a better understanding of the amount of inter- and intraspecific variation that exists in the patterns and behavior of migratory species.

\section{PATTERNS}

The development of miniaturized tracking devices has led to many remarkable discoveries in migration ecology (McKinnon and Love, 2018). Relatively few studies, however, have been able to track enough individuals for long enough periods of time to characterize the full range of migratory behaviors exhibited across the lifespan of an individual, among different demographic groups in a population, or across the entire geographic range of a species (Both et al., 2016; Finch et al., 2017). Indeed, while empirical support for the environmental responsiveness predicted by the modeling studies in our collection is growing, one of the major contributions of our research topic is to provide detailed studies of the patterns of migration in a diverse array of migratory species, including insects (Menz et al.), cartilaginous and bony fishes in freshwater and marine environments (Eldøy et al.; Lennox et al.; Tamario et al.; Thorburn et al.), treefrogs (Borzée et al.), a wide range of birds (Carneiro et al.; Fraser et al.), and large-bodied ungulates (Berg et al.; Brown and Bolger; Found and St. Clair).

Our diversity of study subjects makes clear the overwhelming degree to which migratory behaviors can vary within individuals, as well as among populations and species. For instance, it is perhaps not surprising that ecologically and phylogenetically disparate species might differ in their migratory patterns: 
Egyptian Vultures (Neophron percnopterus) are soaring birds that use terrestrial habitats and avoid overwater crossings (Phipps et al.), whereas extreme migrants such as Upland Sandpipers (Bartramia longicauda) can make non-stop flights of up to $7,600 \mathrm{~km}$ in 7 days over the ocean and across mountain ranges (Hill et al.). It is far more intriguing, however, that two populations of Red-necked Phalaropes (Phalaropus lobatus) breeding immediately adjacent to each other in northern Europe migrate not only to different geographic regions, but different oceans and hemispheres altogether (van Bemmelen et al.). Intra-specific variation is not limited to the routes taken by individuals either, but can also include significant differences in timing between the sexes (Carneiro et al.) or among different nonbreeding sites or parts of a species' range (Phipps et al.; Battley et al.). Similarly, while age-related differences in migratory behavior are not unexpected, we are learning more about how juveniles differ from adults in their migration routes, timing, diet, and physiology (McCabe and Guglielmo; Thorburn et al.). Growing evidence also indicates that dramatic changes in migratory timing and space use can occur during adulthood, even though many species were previously thought to exhibit limited flexibility in their migratory behaviors (Fraser et al.; Senner et al.). Most intriguing, though, is the indication that individuals within populations can vary in the degree to which they show consistent migratory behaviors from year-to-year (Grecian et al.; Verhoeven et al.).

These broad-scale patterns of migratory movements therefore provide additional support for the overarching importance of ecological context in determining migratory behaviors. What thus remains is the identification of those factors most strongly influencing how populations respond to their current ecological context.

\section{PROCESS}

Identifying the specific factors that either constrain or enable individuals and populations to respond to environmental change can be exceedingly difficult given the potential for carry-over effects to connect different life-history stages and geographic regions (Senner et al., 2015). For example, linkages between the quality of the non-breeding and breeding habitats used by an individual can exacerbate the consequences of events in early life (van de Pol et al., 2006). In addition, the same habitat may provide different resources for different groups of individuals, making it difficult to determine the direct connections between individual performance and the apparent quality of a site (Masero et al., 2017). As a result, the study of how migratory patterns are affected by environmental conditions is still in its relative infancy (Piersma, 2011).

A number of studies in our Research Topic investigated the complicated relationships between individual ontogeny and contemporary ecological conditions in the development of migratory behavior. The general pattern that begins to emerge from these studies is one where physiological constraints first interact with inexperience to influence the migratory patterns of juveniles. Two experimental studies of migratory brown trout (Salmo trutta), for example, found that natal growth conditions influence the probability of seaward migration in juveniles, although the effect differed between studies, possibly because food limitations were imposed during different developmental periods (Archer et al.; Shry et al.). Similarly, in migratory songbirds, the slow development of digestive physiology results in sub-optimal physiological performance during an individual's first southbound journey and may underlie well-documented age-related differences in migration speed (McCabe and Guglielmo). Finally, in a migratory shorebird, the Bar-tailed Godwit (Limosa lapponica), once juveniles have made their first southward migrations, individuals may explore widely prior to choosing a non-breeding site to which they will remain largely faithful over the course of the rest of their lives (Battley et al.).

The culmination of an individual's early life experiences therefore appears to be the development of a specific annual routine (Campioni et al., 2020). The development of a regular annual routine often results in surprisingly high repeatability of migratory behaviors (Carneiro et al.; Eldøy et al.; Grecian et al.; Verhoeven et al.). Some species, though, do retain significant flexibility in their migratory behaviors into adulthood, likely in response to variation in environmental conditions, including food, weather, predation risk, and competition (Fraser et al.; Senner et al.). The relative degree to which that flexibility is then employed to respond to current conditions, as opposed to environments experienced during the past, appears to differ depending on the relative severity of the conditions experienced over those two periods. For instance, individuals may alter not only the timing of their subsequent migratory movements (Anderson et al.), but also the length and direction of their movements in response to current food availability and their energetic condition (Brown and Bolger; Holberton et al.). Weather conditions can also play a direct role and drive movements both during migration (de Zwaan et al.) and the non-breeding season (McKinnon et al.). Reversible state effects that result from conditions encountered during previous stages of an individual's annual cycle, on the other hand, may be rarer than once thought and are only likely to occur under specific circumstances (Gow et al.).

The framework that has emerged from our collection of empirical studies, then, is that migratory behaviors are likely determined by a loosely inherited "structure" that can then be honed during development by interactions between physiological constraints, social information, and individual experience, and then repeatedly modified by the environmental conditions that are experienced during adulthood. Taken together, results from the different study systems in our Research Topic suggest that migration may be a system that is more environmentally responsive and potentially less constrained than previously thought. Therefore, what steps can be taken to conserve migratory animals that are exposed to ongoing environmental change?

\section{SYNTHESIS AND APPLICATION}

The studies included in our Research Topic indicate that many characteristics of migratory life-history strategies are shared across a broad range of taxa, including endogenous programs for photoperiodic control of migratory movements (Åkesson and 
Helm) and a role for food, climate, predation, and competition in driving variation in migratory behavior (Berg et al.; Menz et al.). Taken together, these different lines of evidence suggest the potential for a broadly shared migratory syndrome that results less from a shared evolutionary history and more from the common ecological context of breeding in habitats with seasonal pulses of resource availability (Piersma et al., 2005; Dingle and Drake, 2007; Winger et al., 2019).

In this context, the key challenge for the conservation of migrants is that the pace, magnitude, and number of environmental changes that migrants are facing may outstrip the natural variation in flexibility that exists within most species. For example, Tamario et al. reviewed the major threats to migratory fishes and found that populations can simultaneously face overharvesting, rising water temperatures, drying rivers, and increasingly frequent barriers to migratory movements. Concurrent changes can lead to synergistic interactions, which multiply the effects of separate threats and overwhelm potential flexible responses, ultimately impacting population viability and threatening biodiversity. Growing evidence suggests that the key to mitigating the consequences of multiple changes lies in harnessing the significant flexibility that exists in many migratory species. For example, Found and St. Clair examined transitions from migration to residency in wild populations of elk (Cervus canadensis) and found that it was the most flexible individuals that abandoned migration and created humanwildlife conflicts. The flexibility of individuals, however, was part of a more complex shy-bold behavioral syndrome that includes behaviors that can be manipulated through directed management techniques. Thus, individuals can be specifically targeted to encourage them to migrate, thereby reducing the potential for habituation to anthropogenic environments.

We therefore need improved plans for conservation and management that recognize that migration patterns may not be static-migration routes can shift, new stopover sites can be adopted, and the timing of migratory movements can be flexibly molded to environmental conditions as they are experienced. As a result, existing networks of protected sites may not be

\section{REFERENCES}

Alerstam, T. (1979). Wind as selective agent in bird migration. Ornis Scand. 10, 76-93. doi: 10.2307/3676347

Both, C., Bijlsma, R. G., and Ouwehand, J. (2016). Repeatability in spring arrival dates in Pied Flycatchers varies among years and sexes. Ardea 104, 3-21. doi: 10.5253/arde.v104i1.al

Budaev, S., Jørgensen, C., Mangel, M., Eliassen, S., and Giske, J. (2019). Decisionmaking from the animal perspective: bridging ecology and subjective cognition. Front. Ecol. Evol. 7:164. doi: 10.3389/fevo.2019.00164

Campioni, L., Dias, M. P., Granadeiro, J. P., and Catry, P. (2020). An ontogenetic perspective on migratory strategy of a long-lived pelagic seabird: timings and destinations change progressively during maturation. J. Anim. Ecol. 89, 29-43. doi: 10.1111/1365-2656.13044

Dingle, H., and Drake, V. A. (2007). What is migration? BioScience 57, 113-121. doi: 10.1641/B570206

Eichhorn, G., Drent, R. H., Stahl, J., Leito, A., and Alerstam, T. (2009). Skipping the Baltic: the emergence of a dichotomy of alternative spring migration strategies in Russian Barnacle Geese. J. Anim. Ecol. 78, 63-72. doi: $10.1111 /$ j.1365-2656.2008.01485.x adequate under future scenarios of environmental change. One possible approach may be to develop dynamic conservation plans that provide incentives for private landowners to improve conditions for migratory animals along their migration route for short periods of time (Reynolds et al., 2017). Moreover, conservation plans also need to anticipate future changes in resource availability, weather, and predation risk that may be outside the range of environmental conditions for which a population's current migration strategies have evolved. Last, the development and refinement of plans needs horizon scanning that identifies and prioritizes knowledge gaps for different taxa of migratory species (Lennox et al.; Tamario et al.). We hope that the new ideas and discoveries presented in the collection of papers in our Research Topic on Flexibility in the Migration Strategies of Animals will stimulate innovative research and that an improved understanding of organismal flexibility will lead to effective conservation actions for migratory species in the future.

\section{AUTHOR CONTRIBUTIONS}

All authors have made substantial contributions to the editorial and to organizing the Research Topic.

\section{FUNDING}

NS was funded by startup funds from the University of South Carolina. BS was supported by the Norwegian Institute for Nature Research.

\section{ACKNOWLEDGMENTS}

We thank all of the 280 contributing authors for submitting their manuscripts and for making our Research Topic on animal migration a great success. We are grateful to the referees who are acknowledged on the first page of each article, and who provided constructive feedback and thoughtful comments on drafts of the manuscripts. Thank you also to the editorial team at Frontiers in Ecology \& Evolution for their support at all stages of our project.

Finch, T., Butler, S. J., Franco, A. M. A., and Cresswell, W. (2017). Low migratory connectivity is common in long-distance migrant birds. J. Anim. Ecol. 86, 662-673. doi: 10.1111/1365-2656.12635

Gienapp, P., Teplitsky, C., Alho, J. S., Mills, J. A., and Merilä, J. (2008). Climate change and evolution: disentangling environmental and genetic responses. Mol. Ecol. 17, 167-178. doi: 10.1111/j.1365-294X.2007.03413.x

Hebblewhite, M., and Haydon, D. T. (2010). Distinguishing technology from biology: a critical review of the use of GPS telemetry data in ecology. Philos. Trans. R. Soc. B 365, 2303-2312. doi: 10.1098/rstb.201 0.0087

Helm, B., Van Doren, B. M., Hoffmann, D., and Hoffmann, U. (2019). Evolutionary response to climate change in migratory Pied Flycatchers. Curr. Biol. 29, 3714-3719.e4. doi: 10.1016/j.cub.2019.08.072

Kovach, R. P., Gharrett, A. J., and Tallmon, D. A. (2012). Genetic change for earlier migration timing in a pink salmon population. Proc. R. Soc. B 279, 3870-3878. doi: $10.1098 / \mathrm{rspb} .2012 .1158$

Lascelles, B., Sciara, G. N. D., Agardy, T., Cuttelod, A., Eckert, S., Glowka, L., et al. (2014). Migratory marine species: their status, threats and conservation management needs. Aquat. Cons. Mar. Freshw. Ecosyst. 24, 111-127. doi: $10.1002 /$ aqc. 2512 
Lindström, Å., Alerstam, T., and Hedenström, A. (2019). Faster fuelling is the key to faster migration. Nat. Clim. Change 9, 288-289. doi: 10.1038/s41558-019-0443-7

Masero, J. A., Abad-Gómez, J. M., Gutiérrez, J. S., Santiago-Quesada, F., Senner, N. R., Sánchez-Guzmán, J. M., et al. (2017). Wetland salinity induces sexdependent carry-over effects on the individual performance of a long-distance migrant. Sci. Rep. 7:6867. doi: 10.1038/s41598-017-07258-w

McKinnon, E. A., and Love, O. P. (2018). Ten years tracking the migrations of small landbirds: lessons learned in the golden age of bio-logging. Auk 135, 834-856. doi: 10.1642/AUK-17-202.1

Norris, D. R., and Taylor, C. M. (2006). Predicting the consequences of carry-over effects for migratory populations. Biol. Lett. 2, 148-151. doi: $10.1098 / \mathrm{rsbl} .2005 .0397$

Pearce-Higgins, J. W., Brown, D. J., Douglas, D. J. T., Alves, J. A., Bellio, M., Bocher, P., et al. (2017). A global threats overview for Numeniini populations: synthesising expert knowledge for a group of declining migratory birds. Bird Cons. Int. 27, 6-34. doi: 10.1017/S0959270916000678

Pedler, R. D., Ribot, R. F. H., and Bennett, A. T. D. (2018). Long-distance flights and high-risk breeding by nomadic waterbirds on desert salt lakes: nomadic desert waterbirds. Cons. Biol. 32, 216-228. doi: 10.1111/cobi.13007

Piersma, T. (2011). Flyway evolution is too fast to be explained by the modern synthesis: proposals for an 'extended' evolutionary research agenda. J. Ornithol. 152, 151-159. doi: 10.1007/s10336-011-0716-Z

Piersma, T., and Drent, J. (2003). Phenotypic flexibility and the evolution of organismal design. Trends Ecol. Evol. 18, 228-233. doi: 10.1016/S0169-5347(03)00036-3

Piersma, T., Pérez-Tris, J., Mouritsen, H., Bauchinger, U., and Bairlein, F. (2005). Is there a "Migratory Syndrome" common to all migrant birds? Ann. N. Y Acad. Sci. 1046, 282-293. doi: 10.1196/annals.1343.026

Pirotta, E., Mangel, M., Costa, D. P., Goldbogen, J., Harwood, J., Hin, V., et al. (2019). Anthropogenic disturbance in a changing environment: modelling lifetime reproductive success to predict the consequences of multiple stressors on a migratory population. Oikos 128, 1340-1357. doi: 10.1111/oik. 06146

Reynolds, M. D., Sullivan, B. L., Hallstein, E., Matsumoto, S., Kelling, S., Merrifield, M., et al. (2017). Dynamic conservation for migratory species. Sci. Adv. 3:e1700707. doi: 10.1126/sciadv.1700707

Schmaljohann, H., and Both, C. (2017). The limits of modifying migration speed to adjust to climate change. Nat. Clim. Change 7, 573-576. doi: $10.1038 /$ nclimate 3336

Senner, N. R., Conklin, J. R., and Piersma, T. (2015). An ontogenetic perspective on individual differences. Proc. R. Soc. B 282:20151050. doi: $10.1098 / \mathrm{rspb} .2015 .1050$
Taylor, C. M. (2017). The shape of density dependence in fragmented landscapes explains an inverse buffer effect in a migratory songbird. Sci. Rep. 7:14522. doi: 10.1038/s41598-017-15180-4

Taylor, C. M., and Stutchbury, B. J. M. (2016). Effects of breeding versus winter habitat loss and fragmentation on the population dynamics of a migratory songbird. Ecol. Appl. 26, 424-437. doi: 10.1890/14-1410

Tombre, I. M., Oudman, T., Shimmings, P., Griffin, L., and Prop, J. (2019). Northward range expansion in spring-staging Barnacle Geese is a response to climate change and population growth, mediated by individual experience. Glob. Change Biol. 25, 3680-3693. doi: 10.1111/gcb.14793

Tucker, M. A., Böhning-Gaese, K., Fagan, W. F., Fryxell, J. M., Van Moorter, B., Alberts, S. C., et al. (2018). Moving in the Anthropocene: global reductions in terrestrial mammalian movements. Science 359, 466-469. doi: $10.1126 /$ science.aam 9712

van de Pol, M., Bruinzeel, L. W., Heg, D., van der Jeugd, H. P., and Verhulst, S. (2006). A silver spoon for a golden future: long-term effects of natal origin on fitness prospects of oystercatchers (Haematopus ostralegus): fitness consequences of early conditions. J. Anim. Ecol. 75, 616-626. doi: 10.1111/j.1365-2656.2006.01079.x

Verhoeven, M. A., Loonstra, A. H. J., Hooijmeijer, J. C. E. W., Masero, J. A., Piersma, T., and Senner, N. R. (2018). Generational shift in spring staging site use by a long-distance migratory bird. Biol. Lett. 14:20170663. doi: $10.1098 / \mathrm{rsbl} .2017 .0663$

Wiens, J. J. (2016). Climate-related local extinctions are already widespread among plant and animal species. PLoS Biol. 14, e2001104. doi: 10.1371/journal.pbio.2001104

Wilcove, D. S., and Wikelski, M. (2008). Going, going, gone: is animal migration disappearing? PLoS Biol. 6:e188. doi: 10.1371/journal.pbio.0060188

Winger, B. M., Auteri, G. G., Pegan, T. M., and Weeks, B. C. (2019). A long winter for the Red Queen: rethinking the evolution of seasonal migration. Biol. Rev. 94, 737-752. doi: 10.1111/brv.12476

Conflict of Interest: The authors declare that the research was conducted in the absence of any commercial or financial relationships that could be construed as a potential conflict of interest.

Copyright (C) 2020 Senner, Morbey and Sandercock. This is an open-access article distributed under the terms of the Creative Commons Attribution License (CC BY).

The use, distribution or reproduction in other forums is permitted, provided the original author(s) and the copyright owner(s) are credited and that the original publication in this journal is cited, in accordance with accepted academic practice. No use, distribution or reproduction is permitted which does not comply with these terms. 